initially $1.5 \mathrm{~g}$., followed by $1.5 \mathrm{~g}$. four-hourly for two to three days; $1 \mathrm{~g}$. four-hourly for the next two days; $1 \mathrm{~g}$. six-hourly for a final two days.

(b) Sulphaguanidine, succinylsulphathiazole, and phthalylsulphathiazole are of value in ulcerative colitis. The thirdnamed drug is probably the most satisfactory, and has been recommended in oral doses as large as $0.02 \mathrm{~g}$. per kilo of body weight four-hourly for four weeks. Retention enemata of one of these drugs are often useful, 7 to $10 \mathrm{~g}$. being dispensed in $200 \mathrm{ml}$. of water or mucilage.

\section{Civatte's Poikilodermia}

Q.-What is the aetiology of Civatte's disease, and is there any effective treatment? I have a patient who has had patches of brownish discoloration on both cheeks, with scaling and cracking of the skin of the face, for the past two years, associated with irregular menses. A dermatologist diagnosed Civatte's disease and prescribed various lotions, ointments, and later $x$-ray treatment combined with stilboestrol, but the skin is steadily getting worse.

A. - The aetiology of poikilodermia of Civatte is unknown. It usually affects women about the menopausal period and tends to clear spontaneously in the course of a few years. It has been thought to be dependent on some disturbance of endocrine function, adrenal or ovarian, and there does appear to be some response to oestrogen therapy in a few cases. As a rule treatment is without effect. A very similar affection, described by Riehl in 1917 and not limited to women or to this age period, is regarded as being related to the ingestion of fats or the application of creams containing tar and petroleum products.

\section{Ganglion}

Q.-I have a ganglion involving the common extensor sheath on the back of the right wrist of about six months' duration. It causes little inconvenience, but is unsightly in a doctor in practice. What is the correct treatment? Would incision evacuation of contents, and removal of a portion of the posterior wall be likely to lead to permanent disappearance?

A. - To be strictly orthodox complete excision of the entire ganglion should be advised. But when, as in this case, it is the cause of no significant disability and little inconvenience it is tempting either to leave it alone or to attempt subcutaneous rupture of the cyst wall by very firm pressure. If operation is undertaken it should take the form of complete excision, carried out with the aid of a tourniquet under general anaesthesia. This gives the greatest prospect of permanent cure. Simple evacuation with removal of part of the cyst wall, while entailing almost as much inconvenience as complete excision, is far less likely to give permanent relief.

\section{Stilboestrol and Seminoma Testis}

Q.-A patient aged 35 was recently operated on for seminoma of the testicle. There is no evidence at present of metastases, but the possibility cannot be ruled out. Is stilboestrol, or any similar preparation, likely to be effective, as in carcinoma of the prostate? If so, what preparation and what dosage would you recommend?

A.-There is no evidence at present that stilboestrol or any other preparation is of value in cases of seminoma of the testicle. After orchidectomy for seminoma it is advisable to give a course of high-voltage $x$ rays to the aortic lymph nodes.

\section{Reaction to Dental Analgesia}

Q.-A patient had pounding of the heart, gastric distension, and fairly severe pain in the jaw shortly after a tooth extraction. These symptoms, along with polyuria and frequency, continued until the following morning, when he obtained relief by vomiting. This appeared to be a case of acute acidosis due to the local analgesia. Is there any way of counteracting these symptoms?

A.-Reactions following injection analgesia are usually due to the adrenaline and not to the procaine or other synthetic local analgesic employed. Pounding of the heart sometimes occurs after the injection, particularly if any of the solution containing adrenaline is inadvertently injected direct into a blood vessel. In a patient with cardiac disease the signs and symptoms may of course be more severe. Acidosis is not generally produced by local analgesia, but patients not infrequently confuse local analgesia with general anaesthesia and fast for a period beforehand. This fasting may account for acidosis. There is of course no reason why the patient should not have perfectly normal meals before any extraction involving local analgesia.

\section{Induction of Labour}

Q. -What is the best method of induction of labour for use by a general practitioner working in ordinary domiciliary practice? What is the foetal mortality, if any?

A.- It is not stated whether it is desired to induce labour at term or prematurely. In ordinary domiciliary practice the general practitioner would probably be wise to transfer to hospital patients in whom the induction of premature labour seems indicated. When pregnancy appears to be at or after term, the minimum risk to mother and foetus attaches to the induction of labour when the head is engaged, the cervix is effaced, and dilatation has begun. But when these conditions are fulfilled induction is rarely required. The safest method is a "simple induction" with castor oil, enema, and hot bath. Pituitary preparations should be used with caution and are best avoided, while quinine has fallen into disfavour because of reports of foetal death following its use. Surgical methods of induction are not generally suitable for domiciliary practice, although loosening the attachment of the membranes by a sweep of the finger inserted through the cervix is reasonably safe provided the conditions enumerated above are satisfied. The risks of induction of labour to the foetus cannot be stated in general terms; they depend to a large extent on the indication for the operation and the time at which it is done, as well as on the method employed and the state of the lower segment and cervix.

\section{NOTES AND COMMENTS}

Getting Warm in Bed.-Mr. R. D. Mothersole (Bolton) writes : It is often difficult, especially for elderly people, to get warm in bed after getting up during the night. I suppose it is a matter of common knowledge (despite the trend of modern education) that warm-blooded animals get most of the heat they need from their voluntary muscles, which act as slow-combustion stoves and immersion heaters. The fuel, I need hardly say, is glucose. But I find it is less well known, even by doctors, that by tensing one set of muscles against their opponents (e.g., flexors $v$. extensors) especially those of the lower limbs, but the more the better, it is possible to warm up the whole body quickly, with practically no movement of the parts concerned nor disturbance of the bedclothes.

Mind and Skin.-Dr. I. B. SNEDdon writes: My article on "The Mind and the Skin " (March 19, p. 472) was an abridged version of the paper which was given to the Sheffield Medico-Chirurgical Society on Oct. 18, 1948. I should be grateful if this correction could be made.

Ankylosing Spondylitis.-Dr. F. Hernaman-Johnson writes: I regret that the dosage of gold and sodium bismuth tartrate is not made clear in my letter in your issue of April 2 (p. 591). It is $0.001 \mathrm{~g}$. of gold (as printed) and 0.5 grain (not $0.5 \mathrm{~g}$.) of sodium bismuth tartrate.

Correction.-Dr. T. STEPHANides writes: With reference to the article "Ringworm of the Scalp: Treatment by $X$-ray Epilation without Subsequent Local Application " (March 26, p. 523), I would like to point out a typist's error which crept into the text. The statement "Open field 16.6 in $(42 \mathrm{~cm})$ diameter " should of course have read "Open field $16.6 \mathrm{~cm}$. diameter." It will be noted that all the other measurements were given in the metric system only.

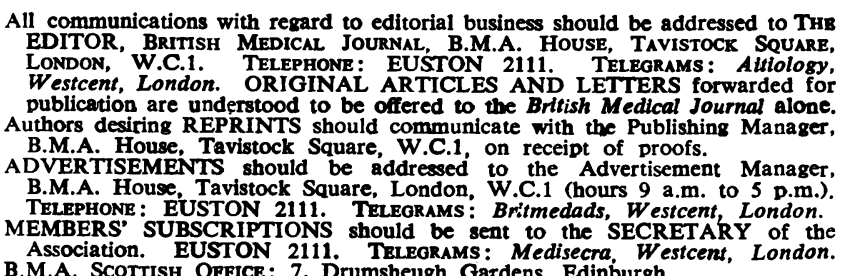

All communications with regard to editorial business should be addressed to THB Altiology, (to brish Medical Journal alone. with the Publishing A. B.M.A. House, Tavistock Square, London, W.C.1 (hours 9 a.m. to 5 p.m.). MEMBERS' SUBSCRIPTIONS should be sent to the 'SECRETARY of the Association. EUSTON 2111. TRLeGraMs: .A. Scotrish OFFICE: 7, Drumsheugh Gardens, Edinburgh. 